Article

\title{
Effect of Atmospheric Cold Plasma Treatments on Reduction of Alternaria Toxins Content in Wheat Flour
}

\author{
Elizabet Janić Hajnal ${ }^{1, *}$, Milan Vukić ${ }^{2,3}{ }^{-1}$, Lato Pezo ${ }^{4}$, Dejan Orčić ${ }^{5}$, Nevena Puač ${ }^{6}$, \\ Nikola Škoro ${ }^{6}{ }^{\circ}$, Ardea Milidrag ${ }^{7}$ and Dragana Šoronja Simović ${ }^{2}$
}

1 Research Center for Technology of Plant Based Food Products, Institute of Food Technology, University of Novi Sad, 21000 Novi Sad, Serbia

2 Department of Carbohydrate Food Engineering, Faculty of Technology Novi Sad, University of Novi Sad, 21000 Novi Sad, Serbia; milan.vukic@tfzv.ues.rs.ba (M.V.); dragana@tf.uns.ac.rs (D.Š.S.)

3 Department of Food Technology, Faculty of Technology Zvornik, University of East Sarajevo, 75400 Zvornik, Bosnia and Herzegovina

4 Institute of General and Physical Chemistry, University of Belgrade, 11000 Belgrade, Serbia; latopezo@gmail.com

5 Department of Chemistry, Biochemistry and Environmental Protection, Faculty of Sciences, University of Novi Sad, 21000 Novi Sad, Serbia; dejan.orcic@dh.uns.ac.rs

6 Laboratory for Gaseous Electronics, Institute of Physics, University of Belgrade, 11080 Belgrade, Serbia; nevena@ipb.ac.rs (N.P.); nskoro@ipb.ac.rs (N.Š.)

7 Chair of general physiology and biophysics, Faculty of Biology, University of Belgrade, 11000 Belgrade, Serbia; ardea304@gmail.com

* Correspondence: elizabet.janich@fins.uns.ac.rs; Tel.: +381-21-485-3624

Received: 26 October 2019; Accepted: 25 November 2019; Published: 3 December 2019

\begin{abstract}
Beside Fusarium toxins, Alternaria toxins are among the most commonly found mycotoxins in wheat and wheat products. Currently, investigations of possibilities of reduction of Alternaria toxins in the wheat-processing chain are limited. Therefore, the aim of this study was to explore the potency of cold atmospheric plasma treatments, as a new non-thermal approach, for reduction of alternariol (AOH), alternariol monomethyl ether (AME) and tentoxin (TEN) content in spiked white wheat flour samples. Samples were treated with plasma generated in the air during $30 \mathrm{~s}$ to $180 \mathrm{~s}$, with an increment step of $30 \mathrm{~s}$, and at four varying distances from the cold plasma source $(6 \mathrm{~mm}$, $21 \mathrm{~mm}, 36 \mathrm{~mm}$ and $51 \mathrm{~mm}$ ). The reduction of the Alternaria toxins content in samples after treatment was monitored by high performance liquid chromatography coupled to tandem mass spectrometry (LC-MS/MS). The maximum reduction of the examined Alternaria toxins was obtained by treatment performed at $6 \mathrm{~mm}$ distance from the plasma source, lasting $180 \mathrm{~s}$, resulting in reductions of $60.6 \%$, $73.8 \%$ and $54.5 \%$ for $\mathrm{AOH}, \mathrm{AME}$ and TEN, respectively. According to the obtained experimental results, five empirical models in the form of the second-order polynomials were developed for the prediction of $\mathrm{AOH}, \mathrm{AME}$ and TEN reduction, as well as the temperature and the moisture content of the wheat flour, that gave a good fit to experimental data and were able to predict the response variables successfully. The developed second-order polynomial models showed high coefficients of determination for prediction of experimental results (between 0.918 and 0.961).
\end{abstract}

Keywords: wheat flour; atmospheric cold plasma; alternariol; alternariol monomethyl ether; tentoxin; LC-MS/MS; mathematical modelling

Key Contribution: This study represents the first report about potency of cold atmospheric plasma treatments in reduction of Alternaria toxins in wheat flour. The results obtained in this study indicated that exposure time of cold plasma treatment had a stronger effect than distance from the discharge on reduction of $\mathrm{AOH}, \mathrm{AME}$ and TEN in wheat flour. Furthermore, longer exposure time at a shorter 
distance of the cold plasma source from the sample, provided a greater degree of reduction of the examined Alternaria toxins.

\section{Introduction}

Wheat (Triticum aestivum $\mathrm{L}$.) is one of the most important food crops, being among the ten most produced commodities [1,2]. The global quality of common wheat and wheat-based products are interrelated to various features such as protein content, protein quality, and presence of contaminants that affect the safety, generally associated with the absence of toxigenic molds and their secondary metabolites, mycotoxins [3]. Fungi of the genus Alternaria (about 250 species), can grow at low temperature. Frequency and ability of this genus to produce a wide range of toxins is a significant and present threat to the health of humans and animals. Due to their prevalence in various foods and cumulative effect [4], mutagenic, teratogenic and possibly carcinogenic effects of Alternaria toxins are possible. According to the European Food Safety Authority (EFSA), major risk factors for Alternaria toxin dietary exposure are cereals and cereal-based products [5]. The genus of Alternaria is commonly present in cereals, resulting in a high possibility of Alternaria toxin incidence and increased risk in affected wheat [6]. Alternaria toxins most frequently present on wheat include alternariol $(\mathrm{AOH})$, alternariol monomethylether (AME), tenuazonic acid (TeA), tentoxin (TEN) and altertoxins (ATXs) [7]. In recent years, many studies showed that the prevalence of Alternaria toxins in wheat from Europe, Africa, Asia, Australia and North and South Americas should not be underestimated [8-13]. Prevention of contamination by Alternaria fungi is the most sensible and cost-saving approach to reducing the risks accompanied with the presence of Alternaria toxins. Still, this approach is not always possible with current agronomic and storage practices, when the environmental conditions favor the growth of toxigenic fungi [8].

Investigations regarding the fate of Alternaria toxins during wheat kernel and wheat flour processing are limited. Only a handful of studies refer to the investigation of the fate of AOH, AME and TeA during wheat cleaning, wheat milling and bread-making [14,15]. The abovementioned studies show that wheat cleaning reduces the content of $\mathrm{AOH}, \mathrm{AME}$ and TeA through the removal of impurities, whereas wheat milling performs only toxin distribution into wheat flour mill streams, and the bread-making procedure only cause a reduction in $\mathrm{AOH}$ content. Further, the extrusion process provides possibilities for reduction of Alternaria toxins. In the investigation of the potential of simple pilot single screw extruder for reduction of $\mathrm{AOH}, \mathrm{AME}$ and TeA in flour of whole wheat, the highest reduction of $\mathrm{AOH}(87.9 \%), \mathrm{AME}(94.5 \%)$ and $\mathrm{TeA}(65.6 \%)$ was achieved when high raw material

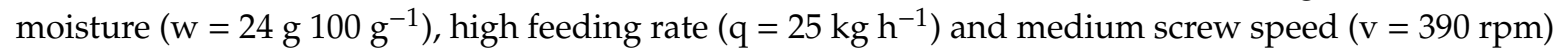
were applied [16].

Recently, application of cold atmospheric plasma got much attention as a novel non-thermal technology for the food industry [17-19]. Some of the advantages of this technology are high efficiency with short treatment time, lack of residues, a low or positive overall impact on the quality of treated food products, and reduced costs when using ambient air as the working gas [20]. Not long ago, the research focus of the plasma treatment was on its effects on pathogenic bacteria [21,22]. Lately, much attention has been paid to studies related to plasma effects on chemical and biological compounds which showed promising results [23-25]. Degradation of mycotoxins is being studied worldwide with different types of plasma sources. Cold atmospheric plasma could possibly overcome the greatest disadvantages of classical techniques and provide a sustainable solution for mycotoxins detoxification [26-29]. Cold plasma is a weakly ionized, quasi-neutral gas with rich chemistry containing a wide variety of highly reactive species and ultraviolet radiation that are shown to be efficient in degradation of mycotoxins. The formation of reactive species in the discharge takes place through complex reaction mechanisms which depend on several factors like type of power supply, frequency, gas used, geometry of the electrode system etc. [30-32]. The choice of the most efficient plasma source is at large extent governed 
also by the type of application. In order to get the desired plasma chemistry for destruction of toxins it is necessary to characterize in detail and optimize the plasma source.

Cold atmospheric plasma in air generates a favorable combination of ions, short- and long-lived reactive oxygen species (ROS) and reactive nitrogen species (RNS) that include $\mathrm{OH} \bullet, \mathrm{O} \bullet, \mathrm{NO}, \mathrm{O}_{3}$, $\mathrm{H}_{2} \mathrm{O}_{2}, \mathrm{NO}_{2}$, etc. [33-36]. By varying the plasma source geometry and type of applied voltage signal discharge can be tuned to produce ozone as one of the prevailing reactive specie which degrades, to a certain degree, mycotoxins on its own $[37,38]$. However, in addition to ozone alone, cold plasma in air leads to the formation of radicals, ROS, RNS and ultraviolet light, culminating in greater mycotoxin degradation efficacy under shorter exposure times than ozone alone. Hence, the importance of other reactive species produced in plasma should not be overlooked [39].

With cold plasma technology, it could possibly be feasible to degrade mycotoxins effectively. Treatment would be more sustainable requiring smaller energy inputs and investment compared to classical techniques. To be applicable to treat wheat flour, cold plasma treatments need to be able to treat the bulk quantities of wheat flour. Multiple intrinsic and extrinsic parameters of wheat flour matrix, including its powdered form, possibly play a role in the effectiveness of cold plasma treatment. One of the plasma sources that can meet these criteria is surface dielectric barrier discharge (SDBD). Technology allows treating the samples at atmospheric pressure with air as the working medium, thereby reducing equipment cost and offering the great advantage of high adaptability and scaling up.

Previous studies indicate that cold atmospheric plasma is a promising technology for degrading of mycotoxins $[27,28,40,41]$. However, none of these studies included Alternaria toxins in wheat flour matrix. Thus, the aim of the present study was to investigate the effects of atmospheric SDBD cold plasma treatments on Alternaria toxin (AOH, AME and TEN) reduction in wheat flour. The experiments were carried out by using SDBD reactor to excite strongly oxidizing cold air plasma above the samples. To process the data obtained, the second order polynomial (SOP) models were used for mathematical modelling. Pattern recognition technique (Principal Component Analysis - PCA) was applied to the experimental data (used as descriptors) to characterize and differentiate among the observed samples. The optimum processing conditions were determined by standard score (SS) evaluation.

\section{Results and Discussion}

\subsection{Optical Emission Spectroscopy and Electrical Characterization of Plasma Source}

Species is generally identified as the main active species responsible for the effects of cold plasma, among which is degradation of chemical and biochemical compounds are atomic oxygen, ozone $\left(\mathrm{O}_{3}\right)$, hydrogen peroxides $\left(\mathrm{H}_{2} \mathrm{O}_{2}\right)$, hydroxyl radicals $(\bullet \mathrm{OH})$, as well as peroxynitrites and nitrogen oxides $[23,24,41]$. Some of the species, such as $\bullet \mathrm{OH}, \mathrm{NO}, \mathrm{O}$, after excitation emit in near UV-visual range and this emission is easily recordable by the optical emission spectroscopy (OES) technique. An emission spectra of the discharge in air was recorded in a wide range of wavelengths from $270 \mathrm{~nm}$ to $860 \mathrm{~nm}$ by using the optical emission spectroscopy (OES) technique. Emission measurements were taken within the first few seconds after the plasma ignition through a quartz window inserted on one side of the plastic box. The spatial angle of the recording included the total volume of the discharge ignited at the lower side of the electrode as well as the volume directly under the electrode plate. The spectrum of the discharge (in arbitrary units) obtained in absence of flour samples is presented in Figure 1 and it gives us qualitative information regarding the chemical species present in the plasma discharge. The most intense lines recorded belong to the $\mathrm{N}_{2}$ Second Positive System band, as expected for the atmospheric air plasma. Relatively lower intensities of peaks associated with atomic oxygen (triplet at $777 \mathrm{~nm}$ ) are due to involvement of $\mathrm{O}$ in creation of $\mathrm{O}_{3}$, and quenching by $\mathrm{N}_{2}$ and $\mathrm{O}_{2}$ molecules [42]. Since the plasma operates in ambient air with certain humidity, $\mathrm{OH}$ radicals are produced mainly through direct $\mathrm{H}_{2} \mathrm{O}$ dissociation. Thus, lines of the $\mathrm{OH}(\mathrm{A}-\mathrm{X})$ band coming from excited $\mathrm{OH}$ radicals are also observed in the recorded spectrum with low emission intensity. Hence, 
the existence of these reactive species can be confirmed by OES characterization of the SDBD unit, thus showing the application feasibility to detoxicate samples with mycotoxins in general.

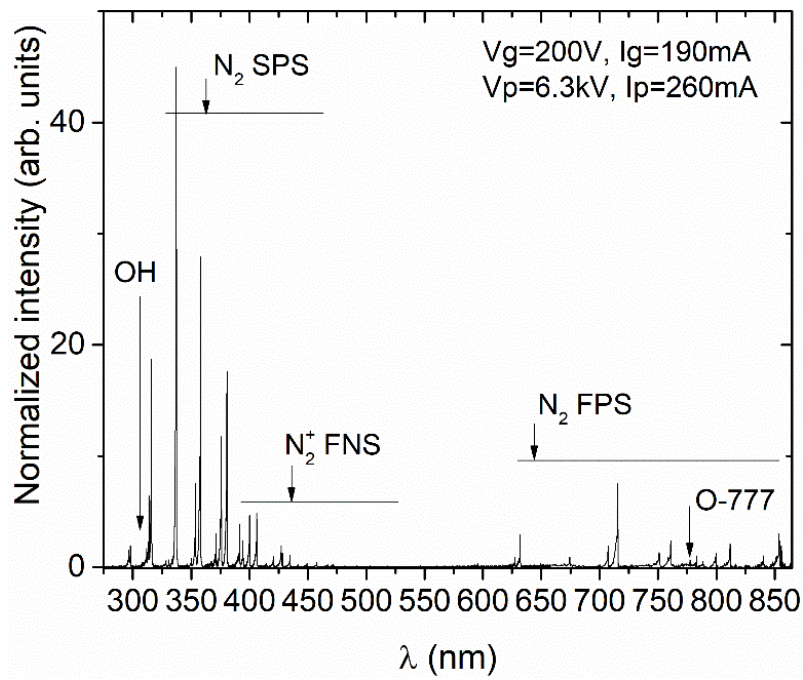

Figure 1. The optical emission spectra of the surface dielectric barrier discharge (SDBD) in atmospheric-pressure air.

The high-voltage (HV) given by the transformer and the current were measured at the point of electrical circuit close to the powered electrode. The dependence of root-mean-square (RMS) values of voltage and current on the variable transformer (variac) voltage are shown in Figure 2a. As expected, for an increase in the variac voltage, there is an increase in both HV and current at the electrode. The maximal RMS values for voltage and current reached with this system were $2400 \mathrm{~V}$ and $0.1 \mathrm{~A}$, respectively.
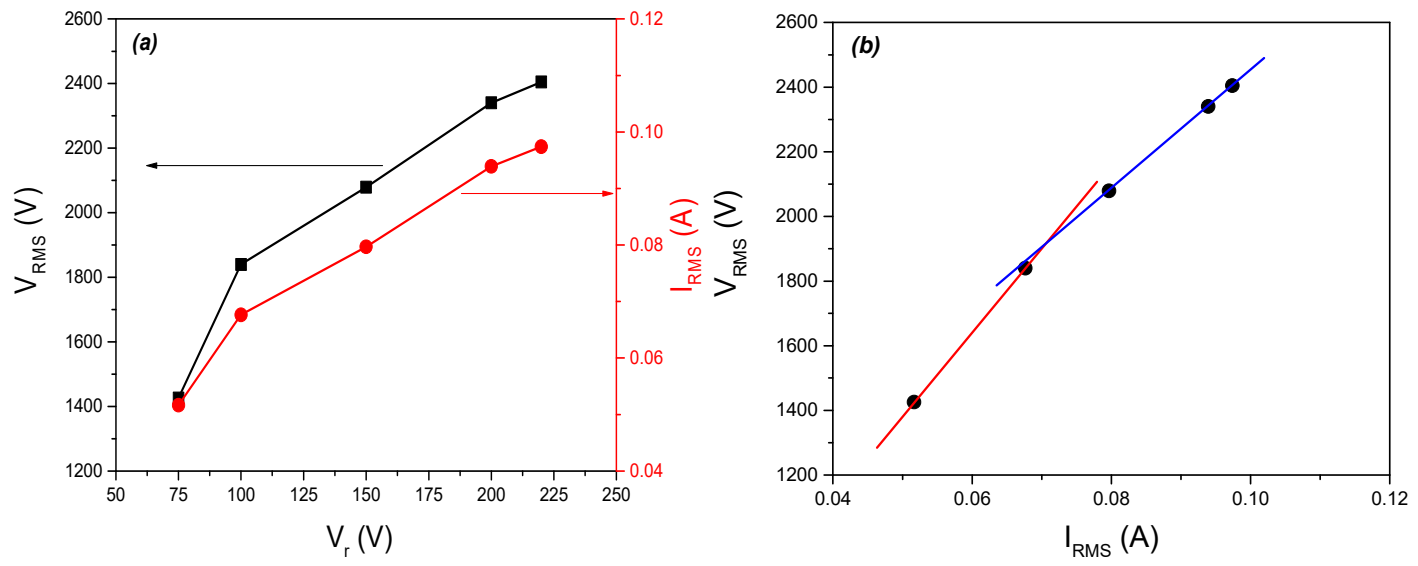

Figure 2. (a) Dependence of $V_{R M S}$ and $I_{R M S}$ values on the voltage values set by the variable transformer; (b) Voltage-current characteristics of the SDBD plasma system. Red and blue lines are guides for the eye for easier detection for impedance change. $V_{\text {RMS }}$ root-mean-square value of voltage;

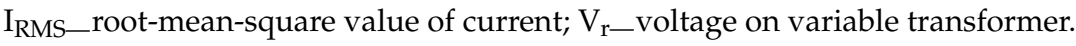

The voltage-current (V-I) characteristics of the system is shown in Figure 2b. At lower voltages immediately after the ignition, plasma does not cover the whole surface of the electrode, but with the increase in the applied voltage, plasma spreads and covers the whole surface uniformly. Spreading of the active plasma surface causes changes in the system impedance. This can be observed as a change from red to blue line in Figure $2 b$. For higher voltages, the impedance is slightly lower, which indicates larger electrode surface covered by homogenous plasma. Generally, when plasma is ignited 
the total impedance of the system is changed. The impedance change towards a lower value can be seen through the effective circuit of the system represented as parallel connection of two complex impedances. One impedance is due to the ignited plasma, which itself represents a complex RLC circuit, and the other one is the impedance of the electrode system. The impedance of the electrode system is due to the capacitance of the electrode system and, to some small extent, due to the resistance of the cables and connectors. Hence, in large area discharges at atmospheric pressure, the changes in the total impedance indicate the area covered by the discharge. Therefore, we have chosen $200 \mathrm{~V}$ as an operating voltage for the flour treatment since the plasma impedance (i.e., total impedance) is constant in this range of voltage-current parameters, since the whole electrode area is covered homogenously. Also, we avoided the highest achieved variac value because of the danger of temperature increase, as well as the change into arcing.

\subsection{Reduction of Alternaria Toxins by Atmospheric Cold Plasma Treatments}

Among the most commonly found Alternaria toxins in wheat [7], AOH, AME, and TEN, were chosen for the focus of this study. The results obtained by the analysis of Alternaria toxins in treated samples suggest that there is a realistic possibility of a significant reduction of toxins by cold atmospheric plasma treatment. The experimental results are presented in Table 1 . The content of toxins was reduced even after only $30 \mathrm{~s}$ of treatment; the reduction ranged from $2.4 \%$ to $44.6 \%$. The reduction rate was dependent on the toxin and sample distance from the plasma. The greatest reduction for all toxins was achieved when samples were placed $6 \mathrm{~mm}$ from plasma discharge, with AME showing the greatest instability. Similar behaviour of other toxins is noticeable from Table 1. Thus, it can be presumed that, in addition to duration and sample distance from the electrode, structural features of toxins affect the treatment efficiency.

Table 1. The results of cold plasma treatments on reduction of Alternaria toxins content in wheat flour.

\begin{tabular}{|c|c|c|c|c|c|c|c|c|}
\hline Trial & $\begin{array}{l}\text { Input } \\
d[\mathrm{~mm}]\end{array}$ & $t[\mathrm{~s}]$ & $\begin{array}{l}\text { Responses } \\
\text { AOH (\%)* }\end{array}$ & $\operatorname{AME}(\%) *$ & TEN $(\%) *$ & $\mathrm{~T}\left({ }^{\circ} \mathrm{C}\right)$ & M (\%) & SS \\
\hline 1 & 6 & 30 & 21.5 & 44.6 & 30.6 & 29.0 & 14.1 & 0.420 \\
\hline 2 & 21 & 30 & 17.0 & 37.0 & 14.4 & 27.0 & 14.1 & 0.327 \\
\hline 3 & 36 & 30 & 8.9 & 32.2 & 13.7 & 25.7 & 14.1 & 0.287 \\
\hline 4 & 51 & 30 & 2.4 & 22.3 & 3.6 & 24.0 & 14.1 & 0.200 \\
\hline 5 & 6 & 60 & 29.1 & 61.3 & 37.6 & 33.2 & 13.8 & 0.539 \\
\hline 6 & 21 & 60 & 21.8 & 49.7 & 22.7 & 27.9 & 14.1 & 0.418 \\
\hline 7 & 36 & 60 & 12.3 & 40.5 & 16.2 & 26.9 & 14.1 & 0.332 \\
\hline 8 & 51 & 60 & 3.0 & 32.9 & 15.4 & 25.9 & 14.1 & 0.275 \\
\hline 9 & 6 & 90 & 32.9 & 61.5 & 38.5 & 37.4 & 13.6 & 0.546 \\
\hline 10 & 21 & 90 & 24.2 & 51.4 & 23.2 & 30.0 & 14.0 & 0.430 \\
\hline 11 & 36 & 90 & 12.6 & 41.8 & 22.7 & 28.7 & 14.1 & 0.350 \\
\hline 12 & 51 & 90 & 6.3 & 35.2 & 18.5 & 27.5 & 14.0 & 0.306 \\
\hline 13 & 6 & 120 & 33.0 & 65.0 & 48.1 & 41.6 & 13.0 & 0.632 \\
\hline 14 & 21 & 120 & 27.5 & 55.9 & 40.7 & 32.0 & 13.8 & 0.534 \\
\hline 15 & 36 & 120 & 16.4 & 48.8 & 39.7 & 30.5 & 14.1 & 0.443 \\
\hline 16 & 51 & 120 & 7.7 & 38.2 & 20.7 & 29.1 & 14.0 & 0.319 \\
\hline 17 & 6 & 150 & 35.0 & 69.2 & 50.2 & 45.9 & 12.6 & 0.675 \\
\hline 18 & 21 & 150 & 30.5 & 56.4 & 44.1 & 34.1 & 13.8 & 0.544 \\
\hline 19 & 36 & 150 & 16.9 & 49.7 & 40 & 32.2 & 13.9 & 0.458 \\
\hline 20 & 51 & 150 & 9.4 & 47.4 & 29.6 & 30.8 & 13.9 & 0.394 \\
\hline 21 & 6 & 180 & 60.7 & 73.8 & 54.5 & 50.0 & 12.3 & 0.800 \\
\hline 22 & 21 & 180 & 47.9 & 62.7 & 48.6 & 36.0 & 13.5 & 0.664 \\
\hline 23 & 36 & 180 & 41.1 & 57.3 & 46.4 & 34.0 & 13.5 & 0.627 \\
\hline 24 & 51 & 180 & 28.6 & 52.7 & 31.8 & 32.5 & 13.9 & 0.476 \\
\hline Polarity & & & + & + & + & - & - & \\
\hline
\end{tabular}

$d$-distance of the cold plasma source to the sample; $t$-time range; $\mathrm{AOH}$-reduction of alternariol; AME-reduction of alternariol monomethyl ether; TEN-reduction of tentoxin; T-temperature of wheat flour sample after treatment; $\mathrm{M}-$ moisture of wheat flour sample after treatment; SS—-standard score. Polarity-negative sign is associated with "the lower the better" criteria, while positive sign is associated with "the higher the better" criteria, as explained in Section 4.10.3. * Values are calculated (see Section 4.9). 
For all treatment times, a similar reduction ratio between studied toxins is noticeable. AME was the most susceptible to cold plasma treatment, followed with TEN and $\mathrm{AOH}$, respectively. There are three possible ways by which cold plasma treatment could exert such a reducing effect on Alternaria toxins content in wheat flour. These are heating, ultraviolet (UV) irradiation, and effects of plasma reactive species. As a non-thermal process, cold atmospheric plasma is designed to minimize heating of the samples. The temperature of SDBD treatments conducted in our experiment never exceeded $50{ }^{\circ} \mathrm{C}$ (the temperature recorded for the longest treatment period at the smallest distance of sample and plasma discharge). Thus, generally the temperature of the sample is well below the temperature required for thermal decomposition of Alternaria toxins. AOH and AME have melting points with decomposition at $350^{\circ} \mathrm{C}$ and $267^{\circ} \mathrm{C}$, respectively, and undergo considerable reduction only after $20 \mathrm{~min}$ at $80^{\circ} \mathrm{C}$ [43]. Hence, the contribution of heat is considered to have a negligible effect on Alternaria toxins degradation. The standard scores presented in Table 1 are calculated according to calculation explained in Section 4.10.3. The larger SS values are assigned to the more efficient toxins reduction (obtained by larger $t$ and smaller $d$ values).

As it can be observed from Figure 1, UV light was emitted due to the $\mathrm{N}_{2}$ species transition in the cold plasma generation process. Still, the emission power in cold plasma generation is not significant enough to be considered as effective for the degradation of mycotoxins, or in our study, Alternaria toxins [43]. Thus, toxin degradation should be attributed to the effects of plasma reactive species.

As earlier demonstrated by OES measurement, when SDBD plasma is excited, ROS and RNS were generated. Since these species accumulate over time of treatment, significant contribution to toxin degradation is possible. Based on the results of other studies, the authors believe that ROS, rather than RNS have a major role in toxin degradation under SDBD treatment. Justification for this claim can be found in the study [41] that reported much lower degradation efficiency of aflatoxin when nitrogen was used as a working medium for cold plasma generation instead of air. Moreover, while Shi et al. [41] were exploring the degradation mechanism, they could not find nitrogen moieties in the degradation products of aflatoxin. Holding to these findings by analogy, the authors expect that ROS are primarily responsible for Alternaria toxin degradation, but do not exclude the possibility of RNS contribution. One of the major ROS generated by cold atmospheric plasma is ozone $\mathrm{O}_{3}$ [44]. Ozone effects on mycotoxins degradation are known $[45,46]$. Several other ROS, atomic oxygen $(\mathrm{O})$, the hydroxyl radical $(\mathrm{OH} \bullet)$, and hydrogen peroxide $\left(\mathrm{H}_{2} \mathrm{O}_{2}\right)$, accompany ozone in the generation of cold atmospheric plasma $[26,39,44]$.

In addition, it was examined whether there is a correlation between process responses. The positive and highly significant correlations between $\mathrm{AOH}, \mathrm{AME}$, TEN and $\mathrm{T}$ can be observed in Table 2. Also, the negative, highly significant correlations between $\mathrm{M}$ and $\mathrm{AOH}, \mathrm{AME}, \mathrm{TEN}$ and $\mathrm{T}$ were obtained in Table 2.

Table 2. The correlation matrix of the process responses, during the cold plasma treatments on wheat flour.

\begin{tabular}{ccccc}
\hline Responses & AME & TEN & T & M \\
\hline AOH & 0.902 & 0.848 & 0.844 & -0.784 \\
AME & & 0.933 & 0.901 & -0.792 \\
TEN & & & 0.861 & -0.751 \\
T & & & & -0.963
\end{tabular}

$\mathrm{AOH}-$ reduction of alternariol; AME—reduction of alternariol monomethyl ether; TEN—reduction of tentoxin; $\mathrm{T}$ - temperature of wheat flour sample after treatment; $\mathrm{M}-$ moisture of wheat flour sample after treatment. * All correlations are statistically significant at $p<0.01$ level.

To characterize and differentiate among the observed samples pattern recognition techniques Principal Component Analysis-PCA were applied to the experimental data (used as descriptors). The points shown in the PCA graphics, which are geometrically close to each other, indicate the similarity of patterns that represent these points. The orientation of the vector describing the variable in 
factor space indicates an increasing trend of these variables, and the length of the vector is proportional to the square of the correlation values between the fitting value for the variable and the variable itself. The angles between corresponding variables indicate the degree of their correlations (small angles corresponding to high correlations). The PCA of the presented data explained that the first two components accounted for $95.47 \%$ of the total variance $(88.68 \%$ and $6.79 \%$, respectively) in the five variables system. Considering the map of the PCA performed on the data, AOH (which contributed $19.5 \%$ of total variance, based on correlations), AME (20.9\%), TEN (19.7\%) and T (21.2\%) exhibited negative scores according to first principal component, whereas $\mathrm{M}(18.7 \%)$ showed a positive score value according to the first principal component (PC1) (Figure 3). The positive contribution to the second principal component (PC2) calculation was observed for: AME (10.9\% of total variance, based on correlations), TEN (18.7\%) and M (48.8\%), while negative scores on the second principal component calculation was observed for $\mathrm{T}(13.3 \%)$.

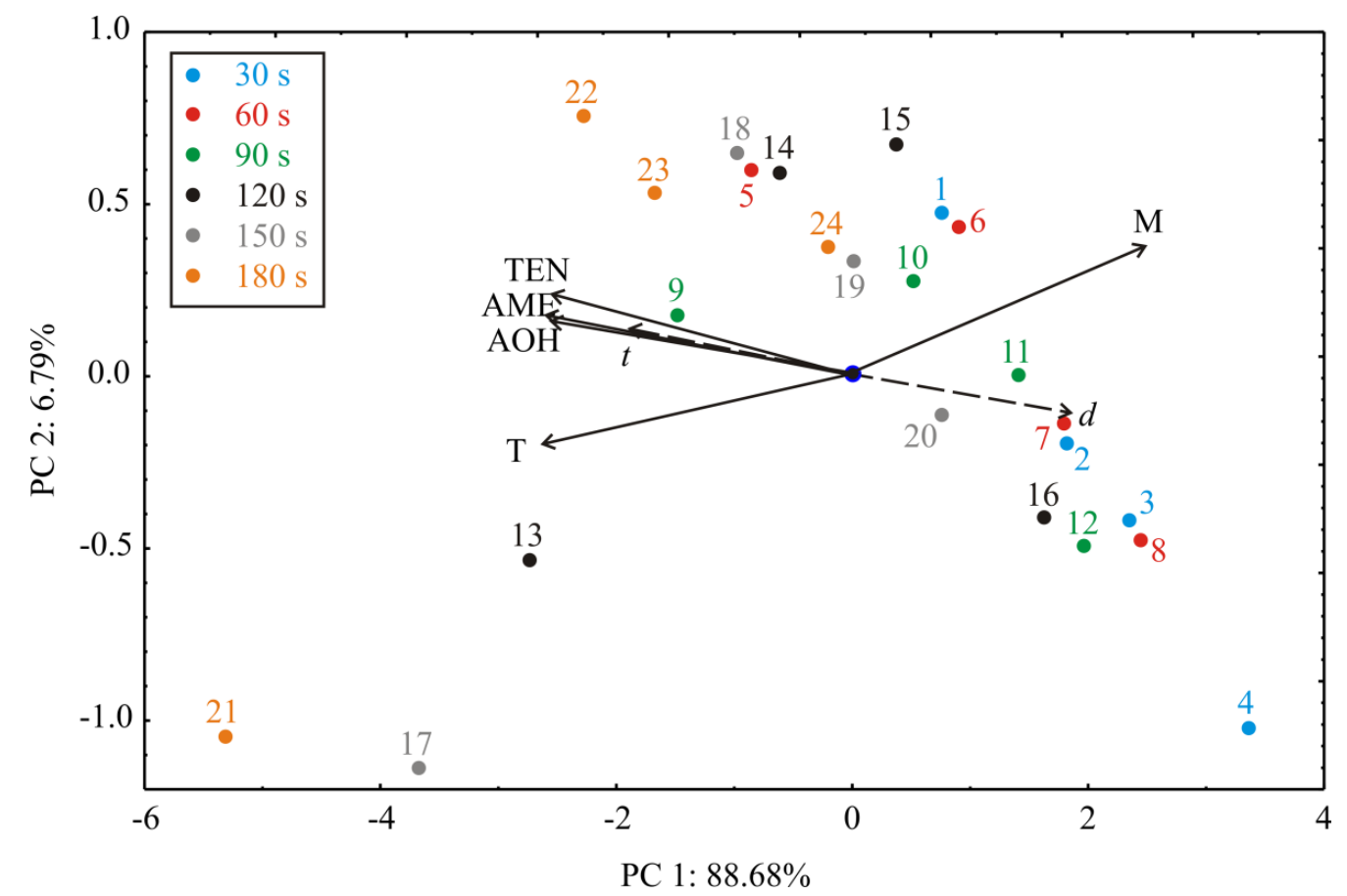

Figure 3. Principal Component Analysis (PCA) ordination of variables based on component correlations. $d$-distance of the cold plasma source to the sample; $t$-time range; $\mathrm{AOH}$-reduction of alternariol; AME-reduction of alternariol monomethyl ether; TEN-reduction of tentoxin; T-temperature of wheat flour sample after treatment; $\mathrm{M}$-moisture of wheat flour sample after treatment.

The influence of processing parameters can be observed in Figure 3. According to the PCA results, the best results in reduction of $\mathrm{AOH}, \mathrm{AME}$ and TEN were observed at $6 \mathrm{~mm}$ plasma source distance when the temperature of wheat flour sample after treatment was higher (this conclusion coincide with the SS results (Table 1.)) compared to other treatments. The processing time vector is oriented in the same direction as the AOH, AME and TEN vectors in the PCA graph, which means that time is positively correlated to the reduction of the $\mathrm{AOH}, \mathrm{AME}$ and TEN, while the treatment variable is negatively correlated to the reduction of the $\mathrm{AOH}, \mathrm{AME}$ and TEN. Groups of samples with the same processing time are coded using different colors, and it is evident that better results in the reduction of the $\mathrm{AOH}, \mathrm{AME}$ and TEN were gained for longer processing time (orange color). The group of samples being treated for the same processing time differs due to the distance from the plasma source (treatment); if the distance to plasma source is shorter, better results in AOH, AME and TEN reduction is gained. 
Further, ANOVA was conducted for obtained Second order polynomial (SOP) models, and output variables were tested against the impact of input variables (Table 3).

Table 3. ANOVA calculation of the process responses, during the cold plasma treatments on wheat flour (sum of squares are presented).

\begin{tabular}{ccccccc}
\hline Term & df & AOH & AME & TEN & T & M \\
\hline$d$ & 1 & $2296.355^{*}$ & $1942.272^{*}$ & $1573.696^{*}$ & $370.657^{*}$ & $1.704^{*}$ \\
$d^{2}$ & 1 & 2.385 & 17.783 & 1.845 & $73.150^{*}$ & $0.570^{*}$ \\
$t$ & 1 & $1892.277^{*}$ & $1675.572 *$ & $2626.082 *$ & $391.053 *$ & $1.808^{*}$ \\
$t^{2}$ & 1 & $344.607^{*}$ & 21.607 & 6.396 & 0.142 & 0.066 \\
$d \times t$ & 1 & 26.331 & 4.890 & 2.185 & $52.807 *$ & $0.890^{*}$ \\
Error & 18 & 356.801 & 148.727 & 321.540 & 41.188 & 0.451 \\
$r^{2}$ & & 0.927 & 0.961 & 0.929 & 0.956 & 0.918 \\
\hline
\end{tabular}

$d$-distance of the cold plasma source to the sample; $t$-time range; AOH-reduction of alternariol; AME—reduction of alternariol monomethyl ether; TEN—reduction of tentoxin; T - temperature of wheat flour sample after treatment; $\mathrm{M}-$ moisture of wheat flour sample after treatment; $\mathrm{df}$ - degrees of freedom; $r^{2}$ —coefficient of determination. * Statistically significant at $p<0.05$ level.

ANOVA analysis revealed that the linear terms of $d$ and $t$ considerably influenced the forming of SOP models for AOH, AME, TEN, T and M calculations, statistically significant at $p<0.05$ level. The quadratic term of $t$ was influential for the $\mathrm{AOH}$ reduction model, while the quadratic term of $d$ was influential for the $\mathrm{T}$ and M SOP models. The interchange term $d \times t$ was influential for the SOP models of $\mathrm{T}$ and $\mathrm{M}$ prediction, statistically significant at $p<0.05$ level. The coefficient of determination $\left(r^{2}\right)$ for the SOP models was rather good (Table 3). According to results presented in Table 3, the higher $r^{2}$ values were attributed to SOP models in which the nonlinear terms were less effective and the linear terms of $d$ and $t$ were more pronounced.

Since the OES measurement performed in the present study can provide only qualitative information about reactive species, it is unclear which specific reactive species play the major role in Alternaria toxin degradation. The most likely scenario is degradation through the synergy of all ROS since they coexist during the treatment and are interconvertible. Besides the conditions already stated, degradation depends on relative humidity, as in humid air higher concentrations of $\mathrm{OH} \bullet$ and $\mathrm{H}_{2} \mathrm{O}_{2}$ are achievable. During the samples treatment, the air was at an intermediate humidity level $(40 \%)$. However, water evaporated from wheat flour samples into the surrounding air of cold plasma, which would have certainly resulted in an increase of $\mathrm{OH} \bullet$ and $\mathrm{H}_{2} \mathrm{O}_{2}$ reactive species (Table 1). Therefore, it is expected that the degradation of Alternaria toxins was through combined effects of the following oxidative species: $\mathrm{OH} \bullet, \mathrm{H}_{2} \mathrm{O}_{2}$, and $\mathrm{O}_{3}$.

Furthermore, the quality of the model fit was tested in Table 4. The higher $r^{2}$ values, and the lower $\chi^{2}, \mathrm{MBE}, \mathrm{RMSE}$ and MPE values show the better fit to the experimental results [47]. The residual analysis of the developed model was also performed. Skewness measures the deviation of the distribution from normal symmetry. If the skewness is clearly different from zero, then the distribution is asymmetrical, while normal distributions are perfectly symmetrical. Kurtosis measures the "peakedness" of a distribution. If the Kurtosis is clearly different than zero, then the distribution is either flatter or more peaked than normal; the Kurtosis of the normal distribution is zero. The average and the standard deviation (SD) and the variance of residuals have also been analysed and shown in Table 4. 
Table 4. Goodness of fit for developed models of the process responses, during the cold plasma treatments on wheat flour.

\begin{tabular}{ccccccccccc}
\hline Responses & $\chi^{2}$ & RMSE & MBE & MPE & $r^{2}$ & Skew & Kurt & Mean & StDev & Var \\
\hline AOH & 18.779 & 3.856 & 0.000 & 19.474 & 0.927 & -0.756 & -0.179 & 0.000 & 3.939 & 15.513 \\
AME & 7.828 & 2.489 & 0.000 & 4.427 & 0.961 & 0.025 & -0.072 & 0.000 & 2.543 & 6.466 \\
TEN & 16.923 & 3.660 & 0.000 & 11.794 & 0.929 & -0.038 & 0.681 & 0.000 & 3.739 & 13.980 \\
T & 2.168 & 1.310 & 0.000 & 3.427 & 0.956 & -0.579 & -0.210 & 0.000 & 1.338 & 1.791 \\
M & 0.024 & 0.137 & 0.000 & 0.816 & 0.918 & 0.515 & -0.177 & 0.000 & 0.140 & 0.020 \\
\hline
\end{tabular}

$\mathrm{AOH}-$ reduction of alternariol; AME—reduction of alternariol monomethyl ether; TEN—reduction of tentoxin; $\mathrm{T}$ - temperature of wheat flour sample after treatment; $\mathrm{M}$ - moisture of wheat flour sample after treatment; $\chi^{2}$-reduced chi-square; RMSE—root mean square error; MBE—-mean bias error; MPE-mean percentage error; $r^{2}$-coefficient of determination; Skew—skeweness; Kurt—kurtoisis; Mean-mean values of residuals; StDev—standard deviation of residuals; Var-variance of residuals.

The residual analysis showed that the mean of residuals were equal to zero, and the standard deviation was between 0.140 and 3.939. These results showed a good approximation to a normal distribution around zero with a probability of $95 \%(2 \times \mathrm{SD})$, which means a good generalization ability of the developed model for the range of observed experimental data.

Increasing the time of treatment increased the plasma degradation efficacy of toxins for all studied toxins in this study. Efficacy for treatment with $6 \mathrm{~mm}$ sample distance ranged from $21.5 \%, 44.6 \%$ and $30.6 \%$ for 30 s plasma exposure to $60.7 \%, 73.8 \%$ and $54.5 \%$ for AOH, AME and TEN respectively, for plasma exposure of $180 \mathrm{~s}$. Observed reductions of Alternaria toxins can be explained with the increase of reactive species during longer treatment times. The increase in toxins degradation with time after $90 \mathrm{~s}$ is smaller than what one would expect based only on the first $60 \mathrm{~s}$ of sample exposure to cold plasma. We partly attribute this lower-than-expected increase in toxin degradation to the possibility that after the toxins are degraded in the surface layer of flour, degradation slows down due to smaller toxins availability in deeper layers. This is a specific wheat flour matrix feature, as samples were in powdered form, treatment time was probably spent on the diffusion of plasma reactive species into sample volume.

The SDBD expressed the filamentary nature of discharge across the electrode surface without directly making contact with samples placed below the electrode. This geometry certainly has an influence on the reactive species fluxes to the sample surfaces and on the effects of ROS and RNS. However, the remote production of ROS and RNS is significantly mediated by the diffusion time to the sample surface during the treatment. In all cases, degradation efficiency increases with increasing treatment time. As it can be seen from Table 1, degradation efficiency is greater for all toxins after an exposure time of $180 \mathrm{~s}$ at $51 \mathrm{~mm}$ than it is after an exposure time of $30 \mathrm{~s}$ and $6 \mathrm{~mm}$ distance from discharge. The extent of Alternaria toxin reduction might be dependent on the structure of mycotoxins in the first place, and then on their molecular mass. For example, AME with a molecular mass of 272.2 Da showed a greater reduction compared to $\mathrm{AOH}$ with a mass of 258.2 Da under the treatments studied. The reduction extent might be affected by their structure since these two mycotoxins share an identical structure with only one different group. AME is a benzochromenone that is $\mathrm{AOH}$ in which the hydroxy group at position 9 has been converted to the corresponding methyl ether. On the other hand, TEN is a natural cyclic tetrapeptide with molecular mass of 414.4 Da and exhibited higher reduction extent under almost all treatments studied compared to $\mathrm{AOH}$. Our findings would be in accordance with the earlier results of other authors (summarized by ten Boch et al. [27]) that showed that the degradation of mycotoxins treated with atmospheric cold plasma did not correlate with a molecular mass. A hypothesis reported by other researchers suggests that mycotoxins with longer aliphatic chains are more sensitive to the influence of cold atmospheric plasma relative to mycotoxins with structures of condensed rings and aliphatic chains and mycotoxins with a compact structure of condensed aromatic rings [27]. Further, Standard Score Analysis (SS) of the five response variables was accomplished in order to find the processing variables (processing time and distance), that give 
optimal values of response variables. The "higher the better" or the "lower the better" criteria have been used according to the sign in "Polarity" raw in Table 1.

The standard score is the average of the five normal scores sum. Each response variable (the reduction of $\mathrm{AOH}, \mathrm{AME}$ and TEN, wheat flour temperature and moisture content) has equal weight, when calculating the SS. The maximum of SS represents the optimal parameters for processing parameters, and also the optimum for response variables. SS analysis showed that the best results were obtained with treatment performed at $6 \mathrm{~mm}$, during $180 \mathrm{~s}$ (SS was equal to 0.800 , reduction of $\mathrm{AOH}$ was $60.6 \%$, reduction of AME and TEN were $73.8 \%$ and $54.5 \%$, respectively, while the obtained wheat flour temperature was $50{ }^{\circ} \mathrm{C}$ and the moisture was $12.3 \%$ ). According to SS results, presented in Table 1 , the satisfactory results for the observed toxins reductions were obtained at a shorter treatment distance $(6 \mathrm{~mm})$ and average processing time (120 and $150 \mathrm{~s})$, at which the SS was 0.632 and 0.675 . Using this set of process variables, relatively low reduction of $\mathrm{AOH}$ was performed. The different approach in optimization could be observed with average treatment distance $(21$ and $36 \mathrm{~mm}$ ) and larger processing time (180 s), where gained SS reached 0.664 and 0.627 . This set of variables lead to relatively low temperature of the wheat flour, but it also gained relatively lower reduction of all studied toxins.

\subsection{Experimental Verification of the Mathematical Models}

In order to test the accuracy of the developed mathematical models, the experimental verification of the model was performed. For the verification of models, the two previously untested values of distance of the cold plasma source to the sample, and the two time range values, within the tested range of values defined in Table 1, were chosen. The optimal process parameters (Trial 21 from Table 1, with $d=6 \mathrm{~mm}$ and $t=180 \mathrm{~s}$ ) were also used in verification of the accuracy of the model. The experimental values of $\mathrm{AOH}, \mathrm{AME}$ and TEN reduction were recorded, as well as the temperature and moisture of the observed material. The values of the response variables were also calculated. The results of the additional experiments and model calculated responses are presented in Table 5. According to the obtained results, only minor differences between the optimal experimental and predicted values for $\mathrm{AOH}, \mathrm{AME}$ and TEN reduction, temperature and moisture content were observed, which means that the developed mathematical model could be used for prediction of the reduction of AOH, AME, TEN and also the temperature and moisture content of wheat flour.

Table 5. Verification of the mathematical models of the process responses, during the cold plasma treatments on wheat flour.

\begin{tabular}{cccccccc}
\hline $\begin{array}{c}\text { Verification } \\
\text { Trial }\end{array}$ & $\begin{array}{c}\boldsymbol{d} \\
(\mathbf{m m})\end{array}$ & $\begin{array}{c}\boldsymbol{t} \\
\mathbf{( s )}\end{array}$ & AOH (\%) & AME (\%) & $\begin{array}{c}\text { TEN } \\
\mathbf{( \% )}\end{array}$ & $\begin{array}{c}\text { T } \\
\left({ }^{\circ} \mathbf{C}\right)\end{array}$ & $\begin{array}{c}\text { M } \\
(\mathbf{\%})\end{array}$ \\
\hline Model & 40 & 45 & 8.370 & 32.179 & 12.858 & 24.809 & 14.200 \\
Exp. & 40 & 45 & 8.498 & 31.980 & 12.754 & 24.767 & 14.249 \\
Model & 15 & 165 & 43.825 & 65.288 & 49.448 & 40.717 & 13.098 \\
Exp. & 15 & 165 & 44.408 & 64.022 & 50.256 & 40.852 & 13.027 \\
Optimal & 6 & 180 & 55.708 & 72.484 & 56.482 & 48.106 & 12.409 \\
\hline
\end{tabular}

$d$-distance of the cold plasma source to the sample; $t$-time range; AOH-reduction of alternariol; AME-reduction of alternariol monomethyl ether; TEN_reduction of tentoxin; T-temperature of wheat flour sample after treatment; $\mathrm{M}-$ moisture of wheat flour sample after treatment. *Values are calculated (see Section 4.9).

\section{Conclusions}

It can be seen that similar results were obtained with all statistical analyses, pointing out that for Trial 21 the best score (SS was 0.800) was gained. The highest reduction of all three Alternaria toxins was achieved with treatment performed at $6 \mathrm{~mm}$, during $180 \mathrm{~s}$. Under these treatments, a reduction of $60.6 \%, 73.8 \%$ and $54.5 \%$, for $\mathrm{AOH}, \mathrm{AME}$ and TEN, respectively, was achieved. The results obtained in this study indicate that cold atmospheric plasma with SDBD excitation has the great potential for reduction of Alternaria toxin content. It can be stated that both investigated factors (time of exposure and distance from discharge) affect degradation efficiency of Alternaria toxins in wheat flour matrix. 
Authors attribute degradation effects to ROS of cold atmospheric plasma, and their synergies. Further, the authors do not exclude the effect of RNS completely. Thus, further research in this direction is needed. The ANOVA results revealed that the linear terms of $d$ and $t$ considerably influenced the forming of SOP models. The second order polynomial models showed good prediction capabilities (the coefficients of determination for the observed variables were between 0.927 and 0.961 ). On the basis of SOP models, the optimal treatment for toxin degradation was obtained at shorter treatment distance $(6 \mathrm{~mm})$ and longer time, with relatively low temperature of the wheat flour. In addition, future research should be related to the investigations of the effect of cold atmospheric plasma with SDBD excitation at optimal treatment conditions on the fate of Alternaria toxins by using naturally contaminated wheat milling products.

\section{Materials and Methods}

\subsection{Material}

For this study, white wheat flour was purchased at the market. The white wheat flour sample was analyzed before the spiking procedure, in order to confirm that it is a blank sample without any of the examined Alternaria toxins. In order to investigate the effect of atmospheric cold plasma on $\mathrm{AOH}$, AME and TEN content, $10 \mathrm{~g}$ of white wheat flour was spiked with examined Alternaria toxins (100 $\mu \mathrm{g}$ $\mathrm{kg}^{-1}$ of each $\mathrm{AOH}, \mathrm{AME}$ and TEN in flour).

\subsection{Treating Spiked Samples with SDBD}

The schematic of experimental set-up is shown in Figure 4. The plasma system consists of SDBD source, active cooler, translucent polypropylene box and a sample holder for a Petri dish of $100 \mathrm{~mm}$ diameter. The SDBD source has 9 stripe electrodes ( 1mm width) placed in comb-like geometry on bottom sides of $2 \mathrm{~mm}$ ceramic dielectric plate (length $70 \mathrm{~mm} \times$ width $40 \mathrm{~mm}$ ). The distance between the stripes is $4 \mathrm{~mm}$. These electrodes are placed along the plate length and connected to a high voltage (powered line from high-voltage (HV) transformer). The top of the dielectric surface is covered with a conductive layer which is connected to the ground line of the HV transformer. The plasma system was actively cooled by a cooler placed on the outside of the box cover on top of the SDBD. The electrical circuit of the plasma system consists of the SDBD source, commercial high-voltage transformer and variac regulator. The variac was powered through the standard electrical grid at the frequency of $50 \mathrm{~Hz}$ and it served as the regulator of HV given by the transformer. Stable plasma ignites in the surrounding air for the input voltage of $200 \mathrm{~V}$ given by the variac.

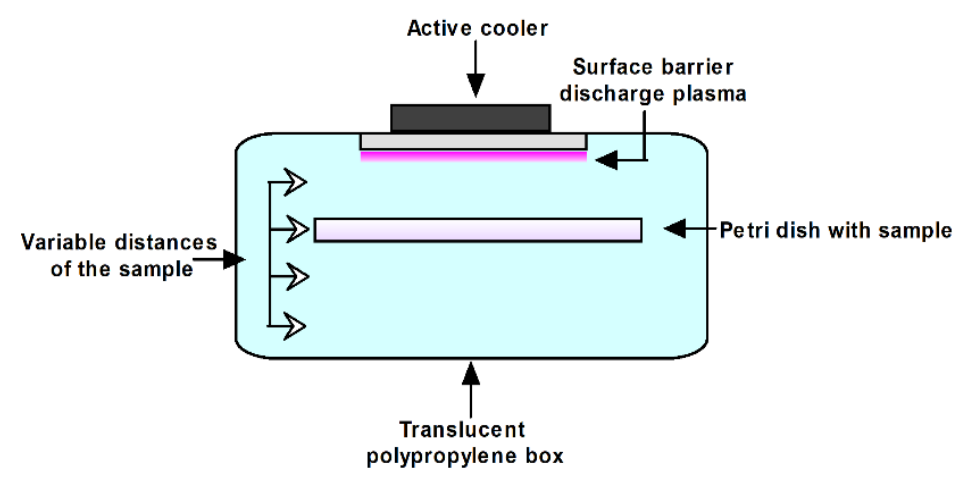

Figure 4. Schematic of experimental setup for SDBD treatment of Alternaria toxins in wheat flour.

The box was sealed to prevent leakage of the plasma species that were generated. An amount of 10 $\mathrm{g}$ of spike white wheat flour was placed in Petri dish and subjected to SDBD treatment. Flour samples were treated for periods of $30 \mathrm{~s}, 60 \mathrm{~s}, 90 \mathrm{~s}, 120 \mathrm{~s}, 150 \mathrm{~s}$ and $180 \mathrm{~s}$ with variable distances from the SDBD 
plasma source, specifically $6 \mathrm{~mm}, 21 \mathrm{~mm}, 36 \mathrm{~mm}$ and $51 \mathrm{~mm}$. The air in the box had a relative humidity (RH) of $45 \pm 1 \%$ at room temperature. The parameters for the experimental set-up are shown in Table 6 .

Table 6. Parameters of the SDBD.

\begin{tabular}{cc}
\hline Parameter $^{*}$ & Value \\
\hline Variac voltage/frequency & $200 \mathrm{~V} / 50 \mathrm{~Hz}$ \\
Applied RMS voltage/current & $2340 \mathrm{~V} / 0.094 \mathrm{~A}$ \\
Sample weight & $10 \mathrm{~g}$ \\
Compartment box size $(\mathrm{L} \times \mathrm{W} \times \mathrm{H})$ & $195 \mathrm{~mm} \times 125 \mathrm{~mm} \times 65 \mathrm{~mm}$ \\
Gas temperature & $\approx 40^{\circ} \mathrm{C}$ \\
\hline
\end{tabular}

* L: length, W: width, H: height.

The temperature of the plasma was measured using an infrared thermometer (Fluke 64 MAX IR Thermometer, Everett, WA, USA). After treatment, the spiked samples were removed from the box, transferred to sealed bag and stored in freezer at $4{ }^{\circ} \mathrm{C}$ until mycotoxin analysis.

\subsection{Optical Emission Spectroscopy}

The optical emission spectroscopy (OES) of the surface barrier discharge in ambient air was captured in an empty polypropylene box, covering the near ultraviolet-visible region (270-850 nm). OES of the surface barrier discharge was acquired with a spectrometer (Shamrock 750, UK) with a detector (Andor DH734 ICCD camera, Belfast, UK) and optical fibers (Thorlabs, Newton, NJ, USA) with Ø200 $\mu \mathrm{m}$ core and collimating lens in UV and VIS range.

\subsection{Electrical Measurements}

Electrical measurements were performed by using a high-voltage probe (Tektronix, P6015A, Beaverton, OR, USA) and current probe (Agilent N2783B) which were placed in the electrical circuit close to the powered electrode. The waveform data were collected by using digital oscilloscope (Agilent, DSOX3014A, Waldbronn, Germany). Additionally, two multimeters were used to measure the voltage and current in the part of the circuit between the variac and high-voltage transformer. The root-mean-square values of voltage and current were used to determine voltage-current characteristics of the plasma system.

\subsection{Moisture Content}

Moisture content in white wheat flour samples before and after appleied treatments was determined using IM 9500 NIR instrument with the optional Flour Module (Perten Instruments, Hagersten, Sweden) and was expressed on the dry basis.

\subsection{Sample Preparation}

The modified method by Siegel et al. [48], described in detail in our previous studies [8,14], was used for sample preparation.

\subsection{Instrumental Conditions}

Alternaria toxins (AOH, AME and TEN) were quantified by high performance liquid chromatography coupled to tandem mass spectrometry (LC-MS/MS) using our previously published method [8] including the equipment and materials, but with some modifications. Namely, quantification of TEN (purity 99.2\%) purchased from Sigma Aldrich (Seelze, Germany) was included in the method. TEN was quantified in negative ionization dynamic selected reactions monitoring mode, and was monitored at a determined retention time of $\pm 1.5 \mathrm{~min}$. Fragmentor voltage and collision energies were optimized during infusion of the pure standard of TEN (concentration of $5 \mu \mathrm{g} \mathrm{mL} \mathrm{m}^{-1}$ ), and the most 
abundant fragment ions were chosen for the selected reaction monitoring. The precursor ion for TEN was $m / z 413.5$, the fragmentor voltage for monitored product ions $(\mathrm{m} / \mathrm{z} 141$ and 271$)$ was $170 \mathrm{~V}$ and the collision energies were $6 \mathrm{~V}$ and $3 \mathrm{~V}$ for $m / z 141$ and $m / z$ 271, respectively. Retention time of TEN was $5.47 \mathrm{~min}$.

\subsection{Method Validation}

The method was validated by an in-house quality control procedure following the guidelines of Commission Decision EC 657/2002 [49]. Method validation was performed in terms of matrix effects, linearity, trueness, precision, limit of detection (LOD) and limit of quantification (LOQ), by the same procedure, as were described in detail in our previous study [14].

The validation data of the analytical method for the determination of selected Alternaria toxins are given in Table 7. During the validation study, matrix-matched calibration (MMC) standards were used to compensate for the matrix effect, i.e., signal suppression or enhancement of the studied Alternaria toxins in the white wheat flour. $\mathrm{AOH}$ and TEN showed signal enhancement, while slight signal suppression was observed for AME.

Table 7. Recovery data of the employed analytical method based on solvent $\left(R_{A}\right)$ and matrix-matched $\left(R_{E}\right)$ calibration curves and matrix effect (SSE).

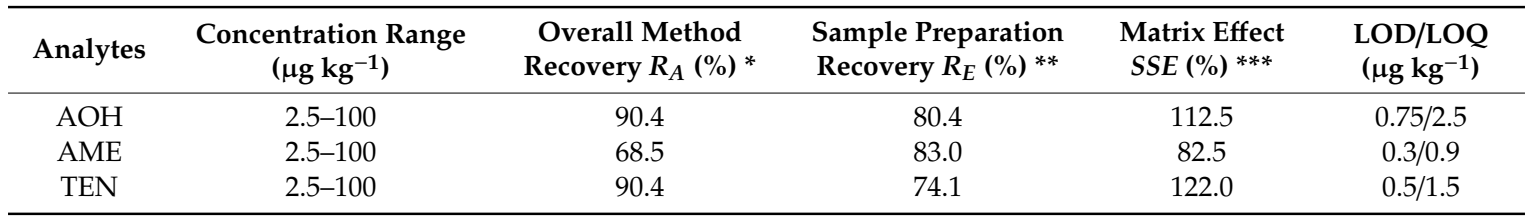

AOH-alternariol; AME-alternariol monomethyl ether; TEN-tentoxin; ${ }^{*}$ Calculated by (slope of spiked sample-prepared curve/slope of solvent calibration curve); ${ }^{* *}$ Calculated by (slope of spiked sample-prepared curve/slope of matrix-matched calibration curve); ${ }^{* * *}$ Calculated by (slope of matrix-matched calibration curve/slope of solvent calibration curve).

The method exhibited good linearity, with correlation coefficients $\left(r^{2}\right)$ above 0.9924 .

Trueness was evaluated through recovery studies. The overall method recoveries $\left(R_{A}\right)$ and the sample preparation recoveries $\left(R_{E}\right)$ for target analytes were calculated as were described in detail in our previous study [14]. It can be seen that the $R_{A}$ and the $R_{E}$ for all target analytes were above $70 \%$, with the exception of $R_{A}$ for AME.

Precision for white wheat flour, expressed as the repeatability and within-laboratory reproducibility (Table 8), gave RSD values within the range of $3.4-11.2 \%$ and $6.1-11.9 \%$, respectively, fulfilling the criteria of RSD $\leq 20 \%$ and indicating a good precision of the developed method.

Table 8. Precision data of the selected Alternaria toxins.

\begin{tabular}{|c|c|c|c|}
\hline Analytes & $\begin{array}{l}\text { Spiking Level } \\
\quad\left(\mu \mathrm{kg}^{-1}\right)\end{array}$ & $\begin{array}{l}\text { Repeatability } \\
(n=6) \text { RSD (\%) }\end{array}$ & $\begin{array}{l}\text { Within-Laboratory Reproducibility } \\
\qquad(\mathrm{n}=3 \times 6) \text { RSDs }(\%)\end{array}$ \\
\hline \multirow{3}{*}{$\mathrm{AOH}$} & 25 & 11.2 & 11.8 \\
\hline & 50 & 7.4 & 8.8 \\
\hline & 100 & 6.0 & 7.7 \\
\hline \multirow{3}{*}{ AME } & 25 & 11.0 & 11.5 \\
\hline & 50 & 7.0 & 7.2 \\
\hline & 100 & 3.1 & 6.1 \\
\hline \multirow{3}{*}{ TEN } & 25 & 10.1 & 11.9 \\
\hline & 50 & 5.3 & 9.8 \\
\hline & 100 & 3.4 & 6.2 \\
\hline
\end{tabular}

AOH—alternariol; AME—alternariol monomethyl ether; TEN—tentoxin; RSD (\%)—relative standard deviation of 6 replicates at three concentration levels using the spiked white wheat flour and the matrix-matched calibration (MMC) curve; RSDs (\%) - relative standard deviation of 6 replicates at three concentration levels using the spiked white wheat flour and the $\mathrm{mmC}$ curve, over the course of three days, using the same instrument and by the same operators. 


\subsection{Alternaria Toxins Determination}

Alternaria toxins were quantified by external matrix-matched calibration procedure in order to eliminate the effect of matrix. Matrix-matched calibration curves were constructed in the concentration range from LOD to $100 \mu \mathrm{g} \mathrm{kg}^{-1}$ for AOH, AME and TEN, respectively. Linearity testing gave values of correlation coefficients $\left(r^{2}\right)$ above 0.9924 in all the investigated ranges. The obtained results were corrected for sample preparation recovery $\left(R_{E}\right)$, and were expressed on a dry matter basis. All samples were prepared and analyzed in triplicates. The reduction of $\mathrm{AOH}, \mathrm{AME}$ and TEN were calculated as:

$$
\text { Reduction of Alternaria toxin }(\%)=100-\left(C_{x} \times 100 / C_{0}\right)
$$

where $\mathrm{C}_{\mathrm{x}}$ is the concentration of Alternaria toxins (AOH, AME and TEN) in the wheat flour sample after tretment; $\mathrm{C}_{0}$ is the initial concentration of Alternaria toxins (AOH, AME and TEN) in spiked wheat flour sample before tretment.

\subsection{Statistical Analysis}

The applied experimental design corresponded to a $4 \times 6$ Latin square design with two factors (Treat. -4 levels and Time -6 levels). The collected data were presented using descriptive statistics tables. The analysis and mathematical modelling was performed using STATISTICA 13.3 (V13.3; StatSoft, Inc.: Tulsa, OK, USA, 2018) [50].

\subsubsection{SOP Models}

According to general recommendations, prior to artificial neural network (ANN) modelling, five SOP models were developed. SOP models were used for the modelling, rather than first order polynomials, due to the complexity of the data, and the pronounced nonlinear dependence between variables. Furthermore, ANOVA was performed, in order to explore the effects of the input variables over the outputs, as well as to justify the later use of the ANN model by the coefficient of determination $\left(r^{2}\right)$.

The SOP model was used for estimation of the main effect of the process variables on responses. The variables used for modelling were the reduction of $\mathrm{AOH}, \mathrm{AME}$ and TEN, whey temperature (Temp) and a moisture of whey (M). The SOP model was fitted to data collected from experimental measurements [51,52]:

$$
Y_{k}=\beta_{0}+\sum_{i=1}^{3} \beta_{i} X_{i}+\sum_{i=1}^{3} \beta_{i i} X_{i}^{2}+\sum_{i=1}^{2} \sum_{j=2}^{3} \beta_{i j} X_{i} \cdot X_{j}, \mathrm{k}=1-8
$$

where: $\beta_{0}, \beta_{\mathrm{i}}, \beta_{\mathrm{ii}}, \beta_{\mathrm{ij}}$, are constant regression coefficients for intercept, linear, quadratic and product term, respectively, $Y_{k}$ is the response variable, while $X_{i}$ and $X_{j}$ are independent variables. The significant terms in the model were found using ANOVA for each dependent variable.

\subsubsection{The Accuracy of the Models}

The numerical verification of the developed models was tested using coefficient of determination $\left(r^{2}\right)$, reduced chi-square $\left(\chi^{2}\right)$, mean bias error (MBE), root mean square error (RMSE) and mean percentage error (MPE). These commonly used parameters can be calculated as follows [47]:

$$
\begin{gathered}
\chi^{2}=\frac{\sum_{i=1}^{N}\left(x_{\text {exp }, i}-x_{\text {pre }, i}\right)^{2}}{N-n} \\
\text { RMSE }=\left[\frac{1}{N} \cdot \sum_{i=1}^{N}\left(x_{\text {pre }, i}-x_{\text {exp }, i}\right)^{2}\right]^{1 / 2}
\end{gathered}
$$




$$
M B E=\frac{1}{N} \cdot \sum_{i=1}^{N}\left(x_{p r e, i}-x_{\exp , i}\right), M P E=\frac{100}{N} \cdot \sum_{i=1}^{N}\left(\frac{\left|x_{p r e, i}-x_{\exp , i}\right|}{x_{\exp , i}}\right)
$$

where $x_{\text {exp }, i}$ stand for the experimental values and $x_{\text {pre }, i}$ are the predicted values by calculating from the model for these measurements. $\mathrm{N}$ and $\mathrm{n}$ are the number of observations and constants, respectively.

\subsubsection{Standard Score Calculation}

Normal scores were calculated for each variable, and were used for complex comparison of observed samples, regarding their technological and chemical properties of the samples listed in Table 1. The ranking procedure between different samples was performed based upon the ratio of raw data and extreme values for each applied assay [53], according to these equations:

$$
\bar{x}_{i}=1-\frac{\max _{i} x_{i}-x_{i}}{\max _{i} x_{i}-\min _{i} x_{i}}, \quad \forall i
$$

in case of "the higher, the better" criteria, or

$$
\bar{x}_{i}=\frac{\max _{i} x_{i}-x_{i}}{\max _{i} x_{i}-\min _{i} x_{i}}, \quad \forall i
$$

in case of "the lower, the better" criteria.

where $x_{i}$ represents the raw data.

Author Contributions: Conceptualization, E.J.H. and M.V.; validation, M.V. and E.J.H.; formal analysis, L.P. and E.J.H.; investigation, M.V., E.J.H., N.P., N.Š. and D.O.; resources, E.J.H., D.O., M.V., N.P., N.Š.; data curation, M.V. and E.J.H.; writing—original draft preparation, M.V., E.J.H. and L.P.; writing—review and editing, M.V., E.J.H., L.P., N.P., N.Š., and D.O.; supervision, E.J.H. and D.Š.S.; funding acquisition, N.P., A.M. and M.V.

Funding: This research was funded by the ministry of Education, Science and Technological Development, Republic of Serbia, as a part of the projects III 46001 and III41011.

Acknowledgments: The authors thanks Ivo Jokić from the company Jokić - invest d.o.o. from Zvornik, Bosnia and Herzegovina who funded the publication of this study.

Conflicts of Interest: The authors declare no conflict of interest.

\section{References}

1. FAOSTAT. Available online: http://fenix.fao.org/faostat/internal/en/\#data/QC/ (accessed on 19 June 2019).

2. Grain Production Worldwide by Type, 2018/19|Statistic. Available online: https://www.statista.com/statistics/ 263977/world-grain-production-by-type/ (accessed on 19 June 2019).

3. Doolotkeldieva, T.D. Microbiological Control of Flour-Manufacture: Dissemination of Mycotoxins Producing Fungi in Cereal Products. Microbiol. Insights 2010, 3, 1-15. [CrossRef]

4. Pinto, E.V.F.; Patriarca, A. Mycotoxigenic Fungi. Mycotoxigenic Fungi: Methods and Protocols 2017, 13-32.

5. EFSA Panel on Contaminants in the Food Chain (CONTAM). Scientific opinion on the risks for animal and public health related to the presence of Alternaria toxins in feed and food. EFSA J. 2011, 9, 2407-2504.

6. EFSA (European Food Safety Authority); Arcella, D.; Eskola, M.; Gómez Ruiz, J.A. Scientific report on the dietary exposure assessment to Alternaria toxins in the European population. EFSA J. 2016, 14, 4654.

7. Walravens, J.; Mikula, H.; Rychlik, M.; Asam, S.; Ediage, E.N.; Di Mavungu, J.D.; Van Landschoot, A.; Vanhaecke, L.; De Saeger, S. Development and validation of an ultra-high-performance liquid chromatography tandem mass spectrometric method for the simultaneous determination of free and conjugated Alternaria toxins in cereal-based foodstuffs. J. Chromatogr. A 2014, 1372, 91-101. [CrossRef]

8. Janić Hajnal, E.; Orčić, D.; Torbica, A.; Kos, J.; Mastilović, J.; Škrinjar, M. Alternaria toxins in wheat from the Autonomous Province of Vojvodina, Serbia: A preliminary survey. Food Addit. Contam. A 2015, 32, 361-370.

9. Müller, M.E.H.; Korn, U. Alternaria mycotoxins in wheat-A 10 years survey in the Northeast of Germany. Food Control 2013, 34, 191-197. [CrossRef] 
10. Xu, W.; Han, X.; Li, F.; Zhang, L. Natural Occurrence of Alternaria Toxins in the 2015 Wheat from Anhui Province, China. Toxins 2016, 8, 308. [CrossRef] [PubMed]

11. Juan, C.; Covarelli, L.; Beccari, G.; Colasante, V.; Mañes, J. Simultaneous analysis of twenty-six mycotoxins in durum wheat grain from Italy. Food Control 2016, 62, 322-329. [CrossRef]

12. Egbontan, A.O.; Afolabi, C.G.; Kehinde, I.A.; Enikuomehin, O.A.; Ezekiel, C.N.; Sulyok, M.; Warth, B.; Krska, R. A mini-survey of moulds and mycotoxins in locally grown and imported wheat grains in Nigeria. Mycotoxin Res. 2017, 33, 59-64. [CrossRef]

13. Scott, P.M.; Zhao, W.; Feng, S.; Lau, B.P.-Y. Alternaria toxins alternariol and alternariol monomethyl ether in grain foods in Canada. Mycotoxin Res. 2012, 28, 261-266. [CrossRef]

14. Janić Hajnal, E.; Mastilović, J.; Bagi, F.; Orčić, D.; Budakov, D.; Kos, J.; Savić, Z. Effect of Wheat Milling Process on the Distribution of Alternaria Toxins. Toxins 2019, 11, 139. [CrossRef]

15. Janić Hajnal, E.; Kos, J.; Orčić, D. Stability of Alternaria toxins during bread-making process. Food Feed Res. 2019, 46, 73-81. [CrossRef]

16. Janić Hajnal, E.; Čolović, R.; Pezo, L.; Orčić, D.; Vukmirović, Đ.; Mastilović, J. Possibility of Alternaria toxins reduction by extrusion processing of whole wheat flour. Food Chem. 2016, 213, 784-790. [CrossRef]

17. Misra, N.N. The contribution of non-thermal and advanced oxidation technologies towards dissipation of pesticide residues. Trends Food Sci. Technol. 2015, 45, 229-244. [CrossRef]

18. Vukić, M.; Vujadinović, D.; Ivanović, M.; Gojković, V.; Grujić, R. Color change of orange and carrot juice blend treated by non-thermal atmospheric plasma. J. Food Process. Preserv. 2018, 42, e13525. [CrossRef]

19. Puač, N.; Gherardi, M.; Shiratani, M. Plasma agriculture: A rapidly emerging field. Plasma Process. Polym. 2018, 15, 1700174. [CrossRef]

20. Misra, N.N.; Tiwari, B.K.; Raghavarao, K.S.M.S.; Cullen, P.J. Nonthermal Plasma Inactivation of Food-Borne Pathogens. Food Eng. Rev. 2011, 3, 159-170. [CrossRef]

21. Niemira, B.A. Cold Plasma Decontamination of Foods. Annu. Rev. Food Sci. Technol. 2012, 3, 125-142. [CrossRef]

22. Kayes, M.M.; Critzer, F.J.; Kelly-Wintenberg, K.; Roth, J.R.; Montie, T.C.; Golden, D.A. Inactivation of Foodborne Pathogens Using A One Atmosphere Uniform Glow Discharge Plasma. Foodborne Pathog. Dis. 2007, 4, 50-59. [CrossRef]

23. Sarangapani, C.; O’Toole, G.; Cullen, P.J.; Bourke, P. Atmospheric cold plasma dissipation efficiency of agrochemicals on blueberries. Innov. Food Sci. Emerg. 2017, 44, 235-241. [CrossRef]

24. Sarangapani, C.; Ziuzina, D.; Behan, P.; Boehm, D.; Gilmore, B.F.; Cullen, P.J.; Bourke, P. Degradation kinetics of cold plasma-treated antibiotics and their antimicrobial activity. Sci. Rep. 2019, 9, 3955. [CrossRef]

25. Misra, N.N.; Kaur, S.; Tiwari, B.K.; Kaur, A.; Singh, N.; Cullen, P.J. Atmospheric pressure cold plasma (ACP) treatment of wheat flour. Food Hydrocolloids 2015, 44, 115-121. [CrossRef]

26. Misra, N.N.; Yadav, B.; Roopesh, M.S.; Jo, C. Cold Plasma for Effective Fungal and Mycotoxin Control in Foods: Mechanisms, Inactivation Effects, and Applications. Compr. Rev. Food Sci. Food Saf. 2019, 18, 106-120. [CrossRef]

27. Ten Bosch, L.; Pfohl, K.; Avramidis, G.; Wieneke, S.; Viöl, W.; Karlovsky, P. Plasma-Based Degradation of Mycotoxins Produced by Fusarium, Aspergillus and Alternaria Species. Toxins 2017, 9, 97. [CrossRef]

28. Siciliano, I.; Spadaro, D.; Prelle, A.; Vallauri, D.; Cavallero, M.; Garibaldi, A.; Gullino, M. Use of Cold Atmospheric Plasma to Detoxify Hazelnuts from Aflatoxins. Toxins 2016, 8, 125. [CrossRef]

29. Hojnik, N.; Modic, M.; Tavčar-Kalcher, G.; Babič, J.; Walsh, J.L.; Cvelbar, U. Mycotoxin Decontamination Efficacy of Atmospheric Pressure Air Plasma. Toxins 2019, 11, 219. [CrossRef]

30. Turner, M. Physics of Cold Plasma. In Cold Plasma in Food and Agriculture; Misra, N.N., Schlüter, O., Cullen, P.J., Eds.; Academic Press: San Diego, CA, USA, 2016; pp. 17-51.

31. Robert, E.; Barbosa, E.; Dozias, S.; Vandamme, M.; Cachoncinlle, C.; Viladrosa, R.; Pouvesle, J.M. Experimental study of a compact nanosecond plasma gun. Plasma Process. Polym. 2009, 6, 795-802. [CrossRef]

32. Maletić, D.; Puač, N.; Malović, G.; Đorđević, A.; Petrović, Z.L. The influence of electrode configuration on light emission profiles and electrical characteristics of an atmospheric-pressure plasma jet. J. Phys. D Appl. Phys. 2017, 50, 145202. [CrossRef]

33. Hasan, M.I.; Walsh, J.L. Numerical investigation of the spatiotemporal distribution of chemical species in an atmospheric surface barrier-discharge. J. Appl. Phys. 2016, 119, 203302. [CrossRef] 
34. Yonemori, S.; Ono, $\mathrm{R}$. Flux of $\mathrm{OH}$ and $\mathrm{O}$ radicals onto a surface by an atmospheric-pressure helium plasma jet measured by laser-induced fluorescence. J. Phys. D Appl. Phys. 2014, 47, 125401. [CrossRef]

35. Graves, D.B. The emerging role of reactive oxygen and nitrogen species in redox biology and some implications for plasma applications to medicine and biology. J. Phys. D Appl. Phys. 2012, 45, 263001. [CrossRef]

36. Pârvulescu, V.I.; Magureanu, M.; Lukes, P. Plasma Chemistry and Catalysis in Gases and Liquids; Wiley-VCH Verlag GmbH \& Co. KGaA: Weinheim, Germany, 2012; pp. 1-401.

37. Wang, L.; Shao, H.; Luo, X.; Wang, R.; Li, Y.; Li, Y.; Luo, Y.; Chen, Z. Effect of Ozone Treatment on Deoxynivalenol and Wheat Quality. PLoS ONE 2016, 11, e0147613. [CrossRef]

38. Olszewski, P.; Li, J.F.; Liu, D.X.; Walsh, J.L. Optimizing the electrical excitation of an atmospheric pressure plasma advanced oxidation process. J. Hazard. Mater. 2014, 279, 60-66. [CrossRef]

39. Misra, N.N.; Moiseev, T.; Patil, S.; Pankaj, S.K.; Bourke, P.; Mosnier, J.P.; Keener, K.M.; Cullen, P.J. Cold Plasma in Modified Atmospheres for Post-harvest Treatment of Strawberries. Food Bioprocess Technol. 2014, 7, 3045-3054. [CrossRef]

40. Park, B.J.; Takatori, K.; Sugita-Konishi, Y.; Kim, I.-H.; Lee, M.-H.; Han, D.-W.; Chung, K.-H.; Hyun, S.O.; Park, J.-C. Degradation of mycotoxins using microwave-induced argon plasma at atmospheric pressure. Surf. Coat. Technol. 2007, 201, 5733-5737. [CrossRef]

41. Shi, H.; Ileleji, K.; Stroshine, R.L.; Keener, K.; Jensen, J.L. Reduction of Aflatoxin in Corn by High Voltage Atmospheric Cold Plasma. Food Bioprocess Technol. 2017, 10, 1042-1052. [CrossRef]

42. Walsh, J.L.; Liu, D.X.; Iza, F.; Rong, M.Z.; Kong, M.G. Contrasting characteristics of sub-microsecond pulsed atmospheric air and atmospheric pressure helium-oxygen glow discharges. J. Phys. D Appl. Phys. 2010, 43, 032001. [CrossRef]

43. Watson, D.H. Natural Toxicants in Food; Sheffield Academic Press: Sheffield, UK, 1998; p. 322.

44. Moiseev, T.; Misra, N.N.; Patil, S.; Cullen, P.J.; Bourke, P.; Keener, K.M.; Mosnier, J.P. Post-discharge gas composition of a large-gap DBD in humid air by UV-Vis absorption spectroscopy. Plasma Sources Sci. Technol. 2014, 23, 065033. [CrossRef]

45. Zorlugenç, B.; Zorlugenç, F.K.; Öztekin, S.; Evliya, I.B. The influence of gaseous ozone and ozonated water on microbial flora and degradation of aflatoxin B1 in dried figs. Food Chem. Toxicol. 2008, 46, 3593-3597. [CrossRef]

46. De Alencar, E.R.; Faroni, L.R.; Soares Nde, F.; da Silva, W.A.; Carvalho, M.C. Efficacy of ozone as a fungicidal and detoxifying agent of aflatoxins in peanuts. J. Sci. Food Agric. 2012, 92, 899-905. [CrossRef]

47. Arsenović, M.; Pezo, L.; Stanković, S.; Radojević, Z. Factor space differentiation of brick clays according to mineral content: Prediction of final brick product quality. Appl. Clay Sci. 2015, 115, 108-114. [CrossRef]

48. Siegel, D.; Feist, M.; Proske, M.; Koch, M.; Nehls, I. Degradation of the Alternaria mycotoxins alternariol, alternariol monomethyl ether, and altenuene upon bread baking. J. Agric. Food Chem. 2010, 58, 9622-9630. [CrossRef]

49. European Commission. Commission Regulation 2002/657/EC of 12 August 2002 implementing council directive 96/23/EC concerning the performance of analytical methods and the interpretation of results. OJEC 2002, 221, 8-36.

50. STATISTICA (Data Analysis Software System), V13.3; StatSoft, Inc.: Tulsa, OK, USA, 2018.

51. Box, G.E.P.; Behnken, D.W. Some New Three Level Designs for the Study of Quantitative Variables. Technometrics 1960, 2, 455-475. [CrossRef]

52. Khuri, A.I.; Mukhopadhyay, S. Response surface methodology. Wiley Interdiscip. Rev. Comput. Stat. 2010, 2, 128-149. [CrossRef]

53. Brlek, T.; Pezo, L.; Voća, N.; Krička, T.; Vukmirović, Đ.; Čolović, R.; Bodroža-Solarov, M. Chemometric approach for assessing the quality of olive cake pellets. Fuel Process. Technol. 2013, 116, 250-256. [CrossRef]

(C) 2019 by the authors. Licensee MDPI, Basel, Switzerland. This article is an open access article distributed under the terms and conditions of the Creative Commons Attribution (CC BY) license (http://creativecommons.org/licenses/by/4.0/). 